\title{
Apelin Signalling: Lineage Marker and Functional Actor of Blood Vessel Formation
}

\author{
Audigier Yves \\ Research Center of Cancerology of Toulouse, \\ UMR 1037 INSERM - Universite Toulouse III,
}

France

\section{Introduction}

G protein-coupled receptors (GPCR) represent a large family of proteins that share a unique membrane topology made of seven transmembrane segments. These receptors are an evolutionary success as they constitute more than $1 \%$ of the genoma. In addition, the same structural archetype has been selected to recognize a large variety of ligands and to activate multiple intracellular cascades via the coupling to different $G$ proteins. Accordingly, $G$ protein-coupled receptors participate in a wide range of physiological functions. The corollary of this physiological importance is that many pathologies are linked to a dysfunction of these signalling pathways. Indeed, half of the pharmacological drugs used to treat human diseases corresponds to molecules which interact with this family of receptors. In this context, the discovery of new receptors not only has an evident physiological interest, but also represents a therapeutic potential by the development of new pharmacological agents. The discovery and history of apelin signalling provides the best example of the close relationship between basic research and its pharmacoclinical implications.

\section{Discovery of apelin signalling}

The discovery of apelin signalling began with the cloning of two orphan G protein-coupled receptors (Masri et al., 2005; Audigier, 2006). The amino acid sequence of these two receptors revealed the presence of seven hydrophobic domains which is in agreement with the unique membrane topology of GPCRs made of seven transmembrane segments (TM). These new GPCRs were cloned by a fishing strategy based on the use of degenerate primers directed against consensus sequences located in the transmembrane segments (TM) (Figure 1).

When searching for subtypes of the vasopressin receptors and using degenerate oligos based on the nucleotide sequence encoding the second and the seventh TM regions, one team cloned by serendipity from human genomic DNA a new orphan receptor that was named APJ (O'Dowd et al., 1993). Northern blot analysis with polyadenylated mRNA revealed an expression in different regions of the rat brain.

In order to determine whether GPCR played a role in early embryogenesis, our laboratory looked for DNA fragments amplified from mRNAs extracted from Xenopus gastrulas between primers located in consensus sequences of TM 3 and TM 6 domains. One amplified fragment was used to clone a novel member of the GPCR family in amphibians that we 
named X-msr for mesenchyme-associated serpentine receptor (Devic et al., 1996). Interestingly, alignment of the protein sequence and molecular phylogeny analysis clearly demonstrated that the amphibian receptor was homologous to the human APJ receptor and represented its amphibian orthologue. In addition, in situ hybridization detected very early transcripts after the midblastula transition, then in the ventro-lateral mesoderm and later in the lateral plate mesoderm.
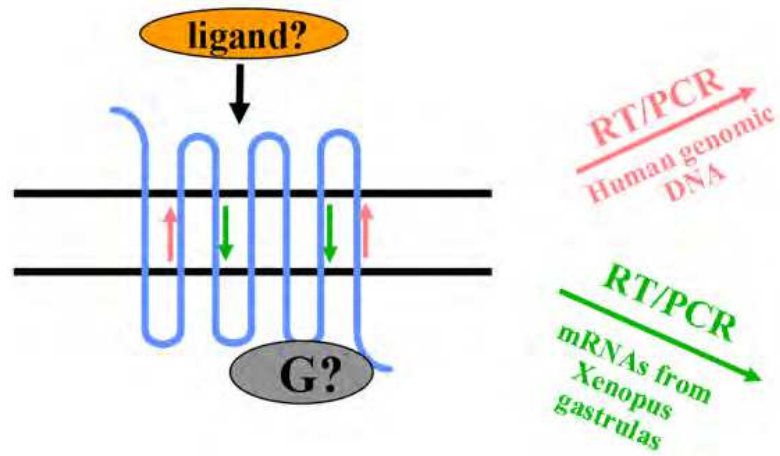

human apj

(O'Dowd et al., 1993)

amphibian X-msr

(Devic et al., 1996)

Fig. 1. Cloning of orphan $\mathrm{G}$ protein-coupled receptors.

The arrows represent the location of the sequences from which the two primers were designed for PCR amplification. The pink arrows correspond to the primers used for cloning of the human receptor APJ. The green arrows correspond to the primers used for cloning of the amphibian receptor X-msr.
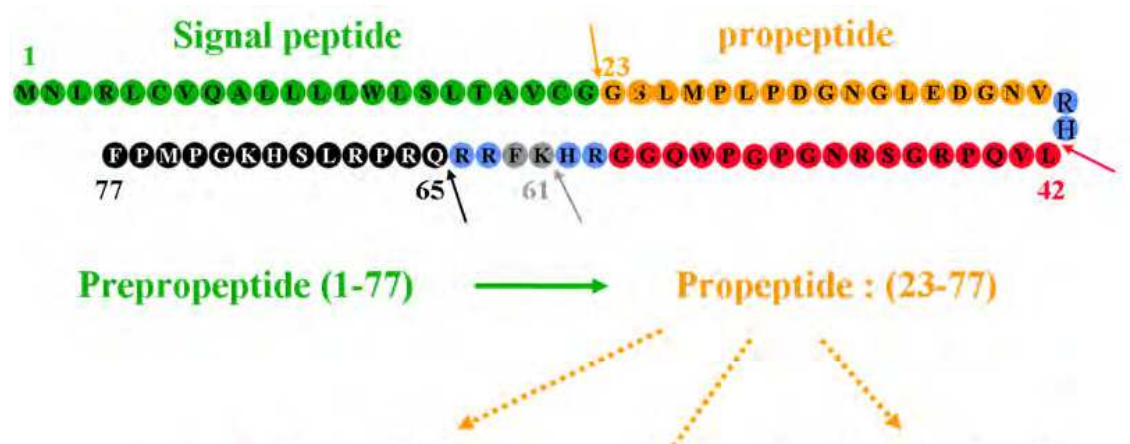

Apelin 36 (42-77)

Apelin 13 (65-77)

\section{Apelin 17 (61-77)}

Fig. 2. Isolation of the endogenous ligand.

Apelin gene codes for a peptide of 77 amino acids (AA), which contains a signal sequence of 22 AA (green). Cleavage of this signal peptide generates a propeptide of 55 AA (orange) having three basic doublets (blue). Proteolytic processing at the level of each basic doublet can produce three fragments of different length : apelin36 (red), apelin17 (grey) and apelin13 (black). 
These receptors remained orphan until the identification of their endogenous ligand isolated several years later from stomach extracts (Tatemoto et al., 1998). The corresponding gene codes for a prepropeptide of 77 aminoacids (Figure 2) containing a signal peptide which addresses the proapelin to the secretory pathway. Then, the propeptide would be processed by proteolytic cleavage at the level of three basic doublets and thus generate apelin fragments of different size: apelin 36, apelin 17 and apelin 13.

\section{Apelin signalling and cell lineages}

\subsection{Embryogenesis and cell lineages}

Although each animal model displays its own advantages and limits, their embryonic development displays strong similarities in the signalling pathways orchestrating and coordinating the migration and the differentiation of the different cell progenitors.

In a schematic manner, embryogenesis begins with a totipotent cell, the fertilized egg, and ends up with the emergence of the different cell types of adult organism and their assembly into specialized organs. The first event is the formation of three embryonic layers, ectoblast, endoblast and mesoblast, which will generate separately and specifically their own cell subpopulations. Gastrulation is the downstream event by which the spatial organization of the cell layers is rearranged with ectoblast outside the embryo, endoblast inside, and the mesoblast in between. Then, each embryonic layer is subdivided into different areas of presumptive territories associated with the commitment of cell progenitors and the formation of cell lineages. Migration of these progenitors and their in situ differentiation will initiate the formation of organ primordia where several cell subtypes will assemble in a spatial and temporal manner in order to form the outline of the future organ.

Mesoblast provides the best example of this regional subdivision linked to the emergence of pluripotent progenitors before the induction of specific cell lineages (Figure 3). Progressively after gastrulation, the mesoblast splits into several territories with different cell potency : axial, paraxial, intermediate and lateral plate mesoderms.

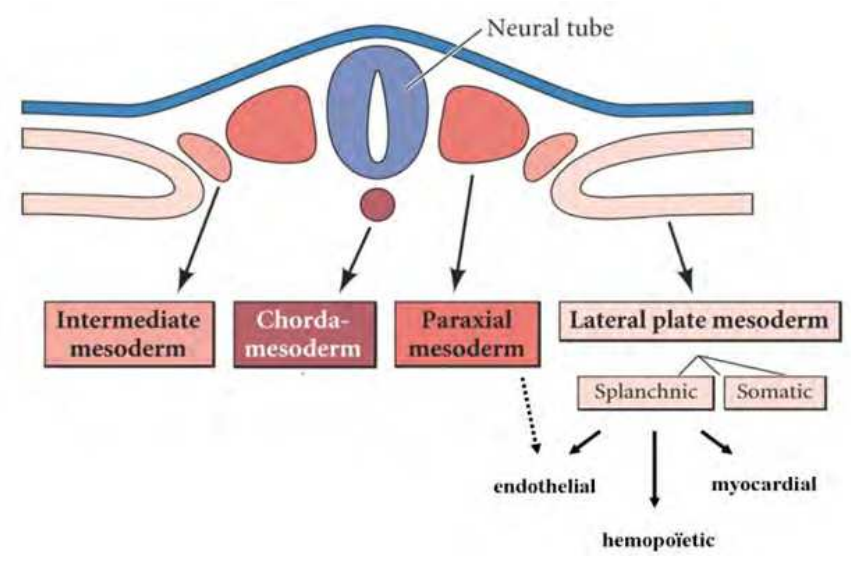

Fig. 3. Mesodermal territories and cell lineages.

After gastrulation, the mesoblast becomes subdivided into different regions that will generate separate progenitors at the origin of specific lineages. A particular emphasis is given for the derivatives of lateral plate mesoderm and the corresponding cell lineages. 
The axial mesoderm strictly corresponds to the formation of a transient structure, the notochord. Segmentation of the paraxial mesoderm gives rise to the somites, which then develop into three distinct regions : the sclerotome, which becomes mesenchymal and is the precursor of vertebrae and ribs, the myotome which forms myoblasts (muscle precursors), and the dermatome precursor of subcutaneous tissue and skin. The intermediate mesoblast is linked to the formation of the urogenital system and serves as the origin of the kidney and gonads. The lateral plate mesoderm is composed of two layers : the somatopleure close to the ectoblast is involved in the formation of connective tissue and bones; the splanchnopleure lying on the endoblast takes part in the formation of the cardiovascular system via three cell lineages corresponding to hemopoïetic, myocardial and endothelial progenitors. In most lineages, commitment of mesodermal cells precedes migration of lineage progenitors to the sites of organ formation. At their final destination, these progenitors in situ differentiate into the corresponding cell subtype.

\subsection{Apelin signalling and endothelial lineage}

In Xenopus (Devic et al., 1996) as well as in mouse (Devic et al., 1999) and zebrafish (Scott et al., 2007), mRNA expression of apelin receptors is observed very early and is localized in the ventrolateral mesoderm at gastrulation stage. Accordingly, apelin receptor may represent a marker of the different lineages originating from this mesodermal territory, such as hemopoïetic, myocardial and endothelial lineages. In addition, apelin signalling may exert a function in the migration or commitment of these cell progenitors.

Our preliminary experiments on the expression pattern of apelin receptor gene from the gastrulation stage to the larval stage clearly established that its later expression was intimately associated with the formation of blood vessels and heart (Devic et al., 1996). Indeed, the transcripts initially in the ventrolateral mesoderm are later detected in the lateral plate mesoderm at neurula stage and then in procardiac tube and forming blood vessels at larval stage. Interestingly, gene expression is strictly localized in the inner endothelium layer. Accordingly, we proposed that receptor gene expression traces an endothelial lineage originating from uncommitted mesodermal cells and ending in endothelial cells (Figure 4).

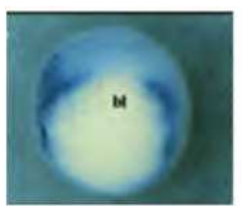

GASTRULA STAGE

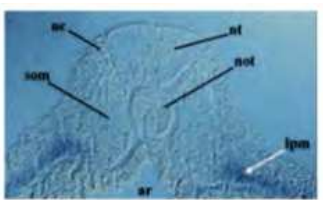

LATE NEURULA STAGE

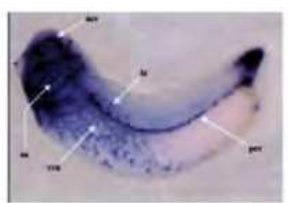

LARVAL STAGE

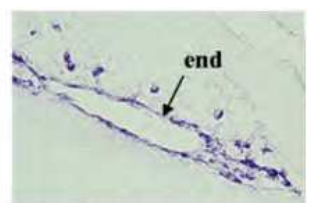

VESSEL SECTION

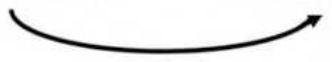

Endothelial cell

Ventrolateral
mesoderm

$$
\begin{gathered}
\text { Lateral plate } \\
\text { mesoderm }
\end{gathered}
$$

Angioblast

Fig. 4. Expression of apelin receptor and endothelial lineage.

The upper part shows the localization of apelin receptor transcripts determined by in situ hybridization during embryogenesis. The arrow from the larval stage shows that the vessel section was performed at this stage. The lower part is a schematic drawing of the cell events occurring along the endothelial lineage. 
Indeed, a subpopulation of mesodermal cells are first specified in endothelial progenitors, the angioblasts, which migrate to the sites of vessel formation. Organization of these endothelial progenitors in tubules and their in situ differentiation into endothelial cells correspond to the formation of the primary vascular network.

The involvement of apelin signalling in this endothelial lineage is further confirmed by the blockade of gene expression using morpholino antisense probes during Xenopus embryogenesis. This experimental inhibition of the ligand or the receptor mRNA leads to a disruption of embryonic vessels (Cox et al., 2006). An additional proof of the vascular role of apelin signalling is revealed by the phenotype of apelin-deficient mice, which corresponds to a retardation of the development of some retinal vessels (Kasai et al., 2008).

\subsection{Apelin signalling and other lineages}

As mentioned before, mesodermal cells from the ventrolateral region not only contributes to endothelial lineage but also to hemopoïetic and myocardial lineages. This common origin together with the pluripotency of these cells have fully challenged the idea of lineage specificity. Indeed, the concept of hemangioblast, a bipotential progenitor of hemopoïetic and endothelial lineages has been validated by various approaches (Jaffredo et al., 2000; Mandal et al., 2004).

Interestingly, such a link between the three lineages has been revealed by a study performed on apelin signalling in Xenopus. Gene inactivation of apelin or its receptor results in a severe phenotype, which corresponds to an attenuated expression of endothelial, hemopoïetic and myocardial markers (Inui et al., 2006). Such an unexpected relationship between endothelial and myocardial lineages is further illustrated by the concomitant expression of apelin receptors by myocardial and endothelial progenitors. But apelin receptors are not simple markers and they also play an active role in the migration of myocardial progenitors : functional inactivation of apelin receptors impairs the migration of these progenitors to the sites of heart formation (Scott et al., 2007; Zeng et al., 2007).

A very recent study has identified a common precursor of endothelial and mesenchymal cells, which was named mesenchymoangioblast. Previously, a late mesodermal precursor expressing Flk1 receptor was characterized by its potential to differentiate into endothelial cells, blood cells and mesenchymal cells (Minasi et al., 2002). However, the early precursors of this Flk1+ mesoderm subpopulation remained to be isolated. Surprisingly, it is expression of apelin receptor that identifies this mesodermal population of early bipotential progenitors giving rise to mesenchymal stem cells and angioblasts (Vodyanik et al., 2010).

\section{Apelin signalling and the formation of blood vessels}

\subsection{The embryonic formation of blood vessels}

The vasculature of the body is a highly organized system and its anatomy is referred to as the vascular tree. Blood vessels are ranging from the simplest structures with a single endothelial layer, the capillaries, to complex structures, the large vessels made of different cell layers (endothelial, mural and elastic), such as aorta (Figure 5).

The first step of blood vessel formation corresponds to the formation of the primary vascular network and is named vasculogenesis (Figure 6). This process results from the migration of endothelial progenitors, the angioblasts, to the sites of vessel formation and their in situ differentiation into endothelial cells. Concomitantly, these angioblasts or endothelial cells assemble together and participate in the formation of tubes or cord-like structures, which will later acquire a lumen. 

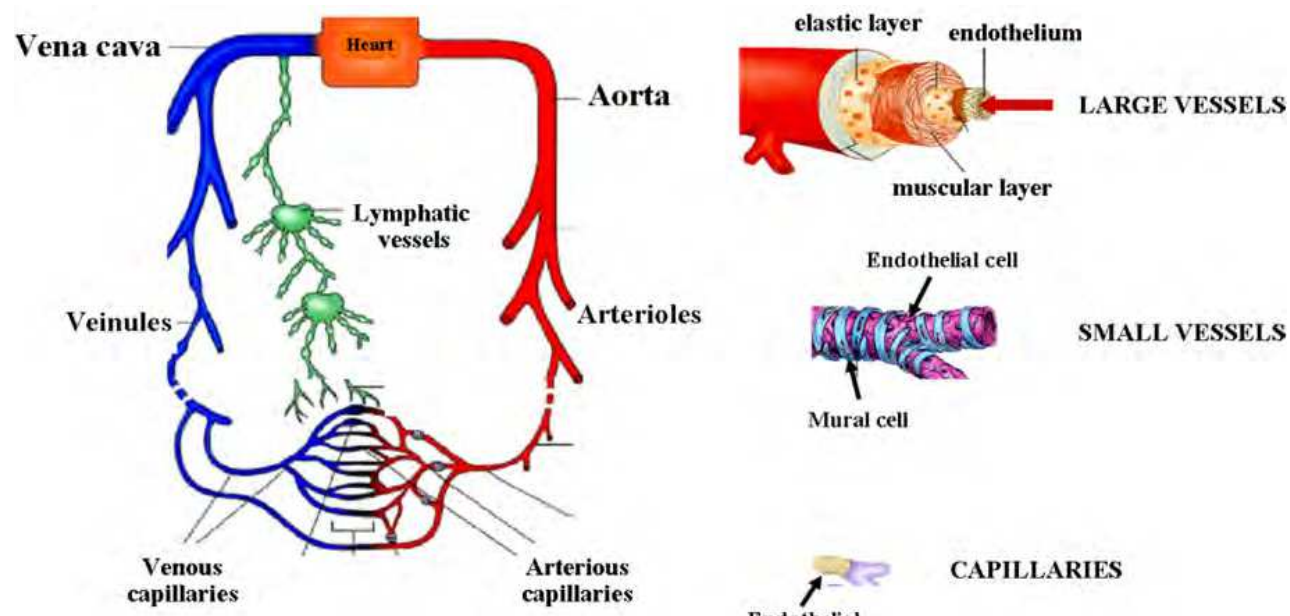

Fig. 5. Vascular tree and vessels.

The left part shows the different arterio-venous elements of the vascular system and includes lymphatic vessels. On the right part are given the vascular structure and layer organization related to the different sizes of vessel .

The second step involves extension and remodelling of the primary network and is named angiogenesis (Figure 6). This process is driven by the increase of embryo size, which requires an adjustment of the oxygen demand and nutrient supply by the vessels to the increased metabolism of the growing tissues and organs. The stability of this mature network is provided by the recruitment of mural cells (pericytes or smooth muscle cells), which will form the second layer of the vessels and induce the quiescence of endothelial cells. Indeed, the proliferation index of the endothelial cells is the lowest among the various cell types of the body.

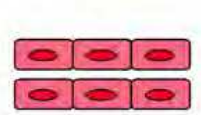

VASCULOGENESIS
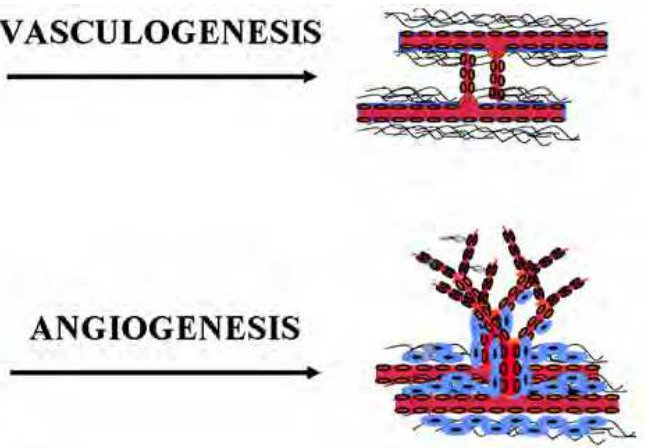

Formation of the primary vascular network (large vessels and plexus)

Formation of the mature vascular network (remodelling/stabilization)

Fig. 6. The two steps of vessel formation.

The upper part describes the first step called vasculogenesis that is involved in the formation of the primary vascular network. The lower part concerns the second step called angiogenesis, which corresponds to remodelling of the primary network and the formation of the mature vascular tree. 
All these cell events are orchestrated and finely tuned by various signalling pathways. The VEGF pathway plays a crucial role during vasculogenesis as well as angiogenesis (Ferrara et al., 2003). Through activation of the VEGFR2, Vascular Endothelial Growth Factor (VEGF) induces the differentiation, proliferation and migration of endothelial cells during vessel formation. In the maturation process, the recruitment of mural cells is mediated by the PDGF pathway (Figure 7).
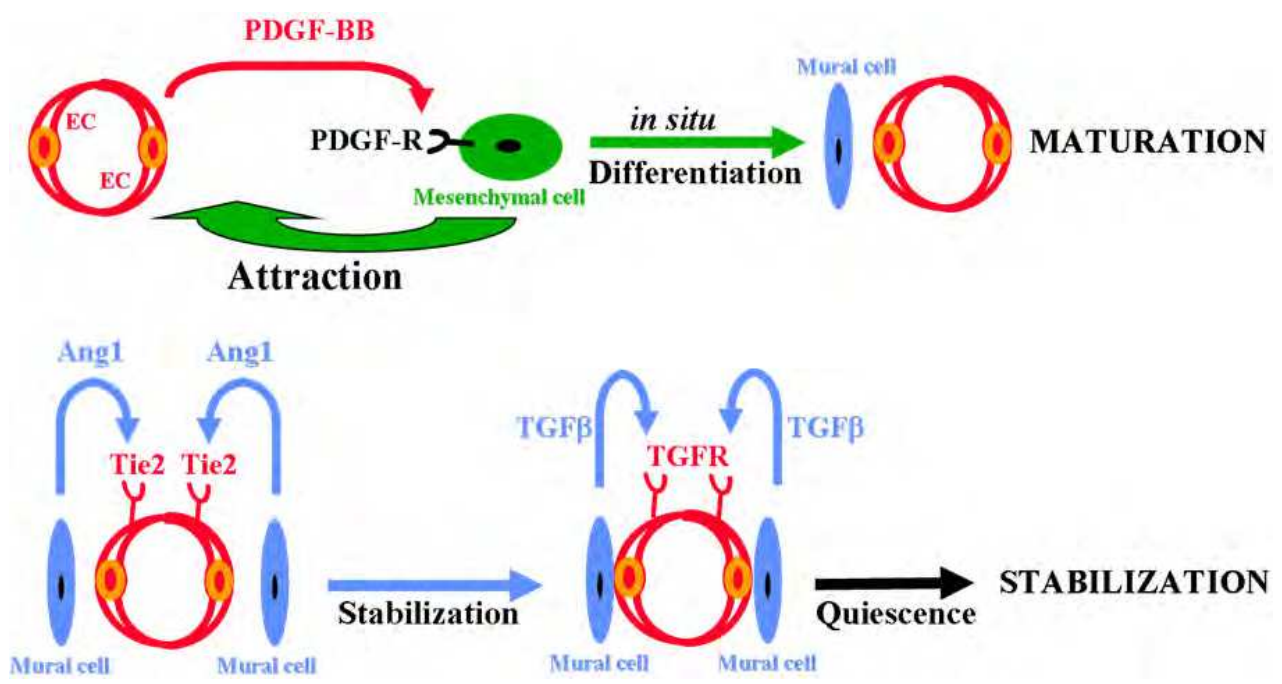

Fig. 7. Maturation and stabilization of vascular structures.

The upper part corresponds to the maturation phase. Endothelial cells (EC) secrete PDGF$\mathrm{BB}$, which is a chemotactic factor for mesenchymal cells. This migration is followed by an in situ differentiation into mural cell. The lower part describes the stabilization phase. The first event is release of angiopoïetin 1 (Ang1) by the mural cell, which then activates its Tie2 receptor expressed at the surface of the endothelial cell. Ang1 pathway strongly reinforces the association between the two cell types. The second event corresponds to the TGF $\beta$ induced quiescence of the endothelial cell whereby TGF $\beta$ released by mural cell activates its receptor expressed by EC.

Endothelial cells release Platelet-Derived Growth Factor (PDGF-BB), thereby attracting the mural cells which express its cognate receptors (Lindahl et al., 1997). The stabilization of the vascular structure is accomplished by a strong interaction between the endothelial cell and the mural cell, which relies on angiopoïetin pathway (Figure 7). Cell adhesion between these two cell types results from the angiopoïetin 1 release by mural cell, which then stimulates its Tie2 receptor expressed at the surface of the endothelial cell (Dumont et al., 1994; Sato et al., 1995; Suri et al., 1996). This constitutive dialogue via the ligand and its receptor is the molecular basis of the stabilization of vessel structure. The concomitant quiescence of the endothelial cell is induced by another factor, TGF $\beta$ which is secreted by the mural cell and activates its receptor expressed at the surface of the endothelial cell (Figure 7).

In parallel, the different caliber of blood vessels must be precisely controlled during the maturation process. Again, the Ang1/Tie2 pathway is a potent regulator of the enlargement of vessel caliber (Suri et al., 1996; Cho et al., 2005; Thurston et al., 2005). 
In the adult organism, physiological and pathological situations are associated with regression or extension of the vascular network (see Figure 12). These changes are initiated by disruption of the mural/endothelial interaction, which involves an another angiopoïetin, Ang2, acting as an endogenous antagonist of Tie2 receptor (Maisonpierre et al., 1997). Accordingly, the alternate ligand use in the same pathway either reinforce or disrupt a cell interaction, which is central in the stability of blood vessel and remodelling of the vascular network.

\subsection{Apelin signalling and the formation of blood vessels}

So far, there is no clear evidence that apelin signalling plays a role during vasculogenesis. As mentioned before, expression of apelin receptors traces the endothelial lineage from unspecified mesodermal cells to differentiated endothelial cells (Devic et al., 1996, 1999). In Xenopus, blockade of gene expression gave controversial results, from full suppression of three cell lineages (Inui 2006) to a restricted angiogenesis defect (Cox et al., 2006). In addition, the phenotypes of gene invalidation in mouse are very mild, ranging from retardation of the formation of retinal network (Kasai et al., 2008) to a mild consequence on blood pressure (Ishida et al., 2004). On the other hand, it has been proposed that the severity of the vascular defects may depend on the genetic background of the invalidated mice. Accordingly, although apelin receptor is a marker of vasculogenesis, it may be a dispensable actor in this early process of vessel formation.

As far as angiogenesis is concerned, the role of apelin signalling is well documented, and a large body of evidence reveals that apelin displays all the properties required for an angiogenic factor. As mentioned before, the endothelial cell is the first cell type which appears during vasculogenesis and represents the organizing center of the vascular structure during angiogenesis. In the adult, proliferation or apoptosis of endothelial cells is also the cell basis of tissue plasticity and vessel remodelling : their proliferation induces extension of the vasculature and their apoptosis promotes regression of the vasculature (see figure 12). Accordingly, it can be assumed that any angiogenic factor must have its cognate receptors expressed by the endothelial cell and that stimulation of these receptors by their ligand promotes a proliferative response. In addition to the characterization of receptor expression by the endothelial cells (Devic et al., 1996, 1999), our laboratory was the first to show that apelin induces the phosphorylation of ERK proteins (Masri et al., 2002, 2006) and behaves as a mitogenic peptide for primary cultured umbilical endothelial cells (Masri et al., 2004) (Figure 8). At the same time, another group published that apelin induces the proliferation of an immortalized endothelial cell line (Kasai et al., 2004).

These results at the cell level have been extended to the whole vessel : a large number of in vitro assays such as matrigel plug assay (Kasai et al., 2004) and in vivo studies such as ectopic apelin expression (Cox et al., 2006) has strongly confirmed the angiogenic activity of apelin peptide (Figure 8). Altogether, these data clearly demonstrate that apelin signalling fulfil at the protein level all the criteria required for an angiogenic pathway and represents a significant actor of physiological angiogenesis during embryonic development.

A more recent study has revealed that apelin also regulates the caliber size of blood vessels by inducing their enlargement (Kidoya et al., 2008). Indeed, we also observed a similar phenomenon during tumour neoangiogenesis, as overexpression of apelin not only promotes an extension of the vascular network but also increases the number of large vessels (Sorli et al., 2007)(see figure 14). Since the Ang1/Tie2 pathway regulates enlargement of vessel caliber, a link between this pathway and apelin signalling was expected. Indeed, Ang1 was found to 
upregulate apelin gene expression in endothelial cells (see figure 17) and apelin expression was increased in Ang1 overexpressing transgenic mice (Kidoya et al., 2008).

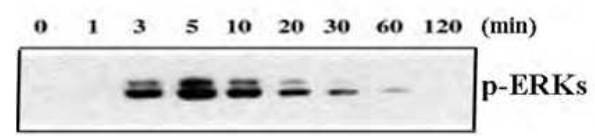

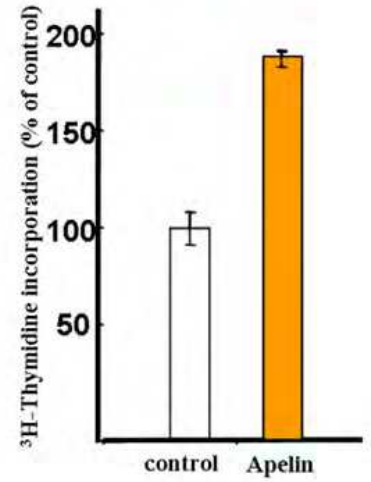

From Masri et al., 2004

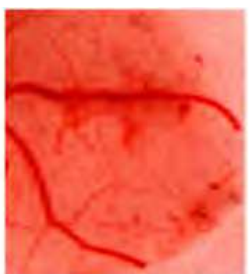

Control

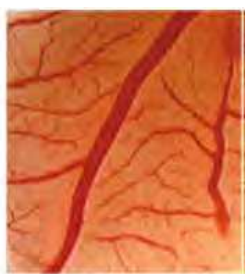

Apelin

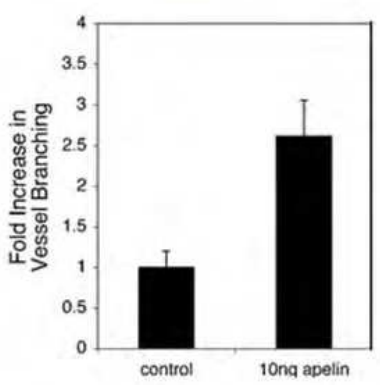

From Cox et al., 2006

Fig. 8. Mitogenic and angiogenic activities of apelin.

The upper left panel shows the time dependent phosphorylation of ERKs induced by apelin (determined by immunoblotting). The lower left panel corresponds to thymidine incorporation, an index of cell proliferation, measured in umbilical endothelial cells in the absence or presence of apelin. The upper right panel shows the angiogenic effect of apelin in the chorioallantoïc membrane of chicken. The lower right panel gives the quantitative analysis based on the calculation of vessel branching.

\subsection{Hypoxia and angiogenesis}

In the adult, the vascular system is quiescent and the proliferative index of endothelium is very low. Several physiological or pathological stimuli may promote the proliferation of endothelial cells and reactivate the angiogenic process. But this reactivation should logically recapitulate the same events and use the same mechanisms operating during the embryonic formation of blood vessels.

The formation of retinal vessels has been the cornerstone for two fruitful hypothesis. A first observation was that extension of the retinal vasculature strictly follows the centrifugal extension of the nervous retina (see Figure 10). A proposed explanation was that a vasotropic substance released by neural cells exerted a chemotactic and proliferative effect on the vessel. As it was already discussed, the concept of a vasotropic substance is simply the ancient denomination for an angiogenic factor. More interestingly, the second hypothesis was on the nature of the driving force initiating the angiogenic process. Indeed, extension of nervous tissue increased the oxygen demand and thus the 
growth-induced hypoxia might be the stimulus for reactivating angiogenesis. However, the molecular link between hypoxia and the angiogenic factor remained to be characterized.

In 1992, Shweiki et al. described that hypoxia was able to upregulate the expression of the VEGF gene, the major angiogenic factor. Such an upregulation of VEGF gene was also reported in the hypoxic regions inside tumours (Plate et al., 1993). Consequently, it established a direct relationship between hypoxia and angiogenesis and provided an explanation for the adjustment of the vascular network to the increased oxygen consumption resulting from tissue growth (Figure 9).

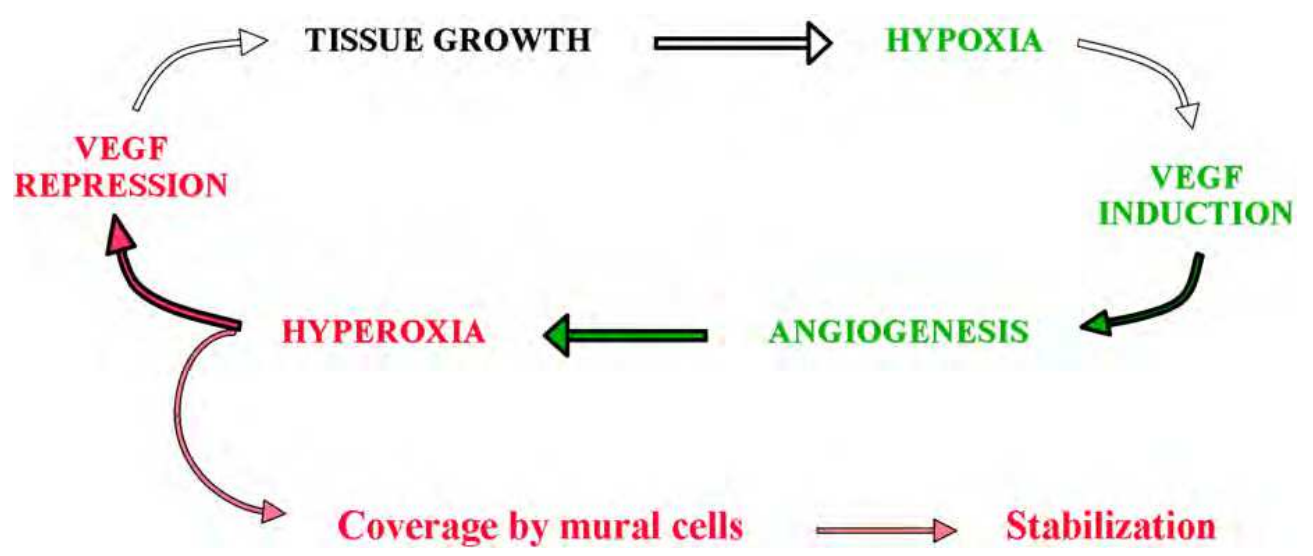

Fig. 9. Hypoxia and vascular homeostasis.

The figure illustrates the relationship between expression levels of VEGF gene and adjustment of vessel number during the angiogenic phase. Tissue growth generates tissue hypoxia which induces expression of VEGF gene. VEGF stimulates the formation of new vessels which become excendentary and thus the subsequent hyperoxia downregulates VEGF expression. Different cycles of VEGF upregulation and downregulation occur until formation of the definitive network, which is then stabilized by coverage of the endothelial layer by mural cells.

More recently, the various intermediates involved in the transduction of the hypoxic stimulus and overexpression of the VEGF gene have been characterized. The central protein in this regulation is a heterodimeric transcription factor named Hypoxia Inducible Factor 1 (HIF-1). The protein complex consists of a hypoxically inducible subunit HIF-1 $\alpha$ and a constitutively expressed subunit HIF-1 $\beta$ (Wang et al., 1995). Although the transcription and the synthesis of HIF-1 $\alpha$ are constitutive, it has in normoxia a short half-life due to its targeting to and degradation by the proteasome (Wang et al., 1995). Several posttranslational modifications are necessary for targeting the $\alpha$ subunit to the proteasome, but the most relevant is hydroxylation by prolyl hydroxylases (Masson et al., 2001). Indeed, this oxygen-dependent modification initiates a complex series of molecular interactions which ultimately end up in subunit ubiquitination and proteasome degradation. As hydroxylation requires sufficient oxygen levels, this reaction is inhibited in hypoxic conditions. Consequently, HIF-1 $\alpha$ becomes stabilized and translocates to the nucleus where its 
dimerization with HIF-1 $\beta$ generates a transcriptionally active HIF complex (Huang et al., 1996; Kallio et al., 1997).

As many transcription factors, HIF complex selectively recognizes and binds to discrete DNA sequences located in the promoter or enhancer elements of target genes. These consensus sequences have been identified and named Hypoxia Responsive Elements (HRE)(Semenza et al., 1994). As it could be anticipated, the presence of HRE was detected in the genes encoding angiogenic factors, notably that of the VEGF gene (Levy et al., 1995).

All these results provide a very simple and adaptative mechanism, which ensures a direct causal relationship between hypoxia and angiogenesis in order to achieve a fine homeostasis between oxygen demand of growing tissues and oxygen supply by blood vessels.

\subsection{Hypoxia and apelin expression}

The corollary of the previous findings is that the gene encoding any angiogenic factor has to contain HRE sequences and to be induced by hypoxia.

In view of the angiogenic role of apelin, several studies have been performed in order to characterize an upregulation of apelin gene under hypoxic conditions. The results clearly showed that hypoxia increases apelin mRNA levels via HIF protein in different cell types, but with varying intensity ranging from a 2-fold to 30-fold increase (Cox et al., 2006; Sorli et al., 2007; Ronkainen et al., 2007; Glassford et al., 2007; Sheikh et al., 2008; Eyries et al., 2008). In addition, gene upregulation at the mRNA level is accompanied by a subsequent increase of peptide synthesis and secretion (Ronkainen et al., 2007; Sheikh et al., 2007).

A bioinformatic analysis has corroborated these experimental data by identifying the presence of putative HRE sequences in apelin gene (Cox et al., 2006). In addition, a functional HRE was mapped within the first intron by reporter constructs and the binding of HIF- $1 \alpha$ to this HRE was demonstrated by chromatin immunoprecipitation (Eyries et al., 2008).

\subsection{Retinal vessels and endothelial subpopulations}

The retinal vasculature of mouse represents an interesting model system used for the study of blood vessel formation. In contrast to the embryo, the vessels are readily accessible as their formation occurs postnatally, and whole mount retinas allow to characterize the spatio-temporal expression of genes by in situ hybridization or proteins by immunohistochemistry (Figure 10).

Interestingly, a study on the formation of retinal vessels has revealed the presence of two distinct endothelial populations, which differ in their morphology and their functional specialization (Gerhardt et al., 2003). Endothelial cells at the front of migrating vessels, called tip cells, possess cell protrusions (filipodia) and their function is specialized in the decoding of chemotactic signals and polarized extension of the network (Figure 11). Underneath, the other endothelial cells, called stalk cells, do not have a particular morphology and their function is to proliferate in order to provide the new endothelial cells that are required for extension of retinal vasculature (Figure 11).

\subsection{Apelin signalling and endothelial subpopulations}

In this retinal model, the spatio-temporal expression of apelin and its receptor displays a very interesting pattern (Saint-Geniez et al., 2002). Ligand and receptor mRNA expression is selectively upregulated during the formation of retinal vessels and downregulated after 
maturation and stabilization of the retinal network (Figure 10). Again, these observations confirm that apelin signalling is activated during the angiogenic phase and desactivated when the vessels become quiescent.
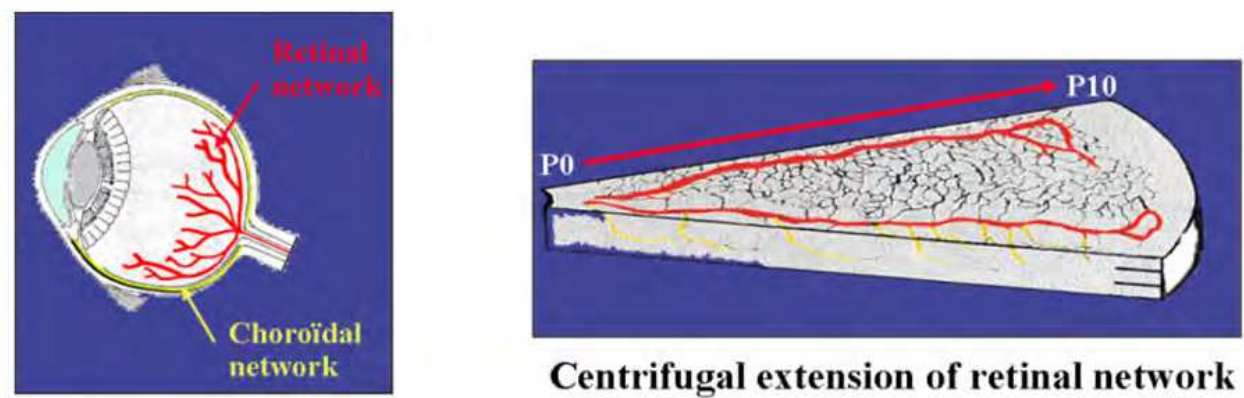

Centrifugal extension of retinal network
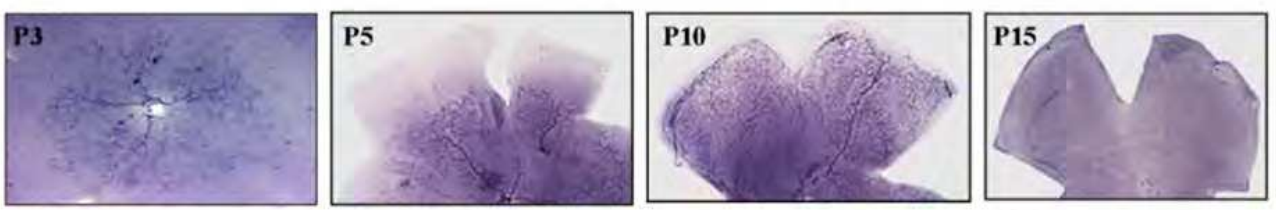

Expression of apelin receptor during formation of retinal vessels

Fig. 10. Retinal model and apelin signalling.

Upper panel illustrates the vascular networks of retina. Nervous retina is irrigated by two vascular networks, the retinal vessels and the choroïdal vessels. In mouse, the postnatal formation of the retinal network proceeds in a centrifugal manner from optic disk at birth to the periphery at postnatal day 10 (P10). Lower panel shows the spatio-temporal expression of apelin receptor gene during formation of retinal vessels. Note the downregulation observed after the onset and stabilization of the retinal network at P15.

In addition, expression pattern of apelin and its receptor was spatially different, even inside the endothelium (Saint-Geniez et al., 2002) (Figure 11). Apelin expressing endothelial cells were localized at the leading edge of the retinal vascular network, whereas receptor expression was mainly observed in the underneath endothelial cells. Using a specific fluorescent lectin for labelling endothelial cells, we detected high apelin expression levels in tip cells easily recognized by their filipodia. On the other hand, we were unable to detect apelin receptor transcripts in this first row of endothelial cells, whereas receptor expression was observed in the other endothelial cells of the vascular network, previously referred to as stalk cells (Sorli et al., 2006).

According to this expression pattern and the proposed role of VEGF as the chemotactic signal for the polarized extension of the vascular network, we proposed a model in which apelin would be the downstream molecule transmitting the proliferative signal from tip cells to downstream stalk cells. 

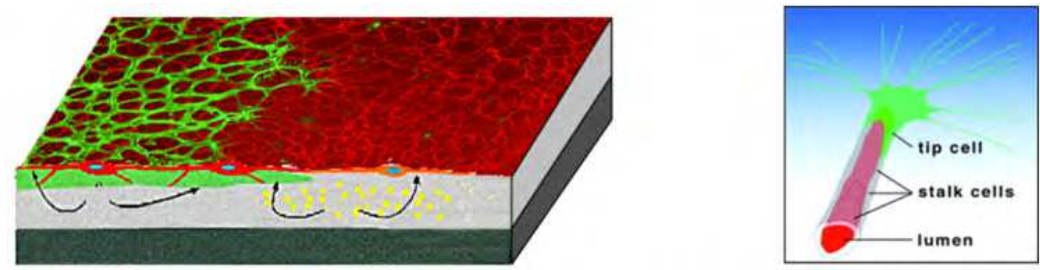

From Gerhardt et al., 2003

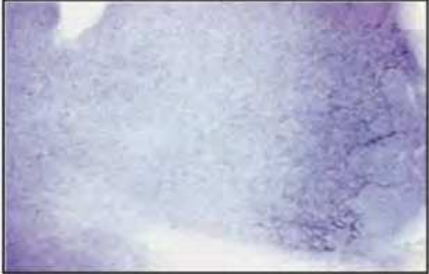

Apelin is expressed in tip cells

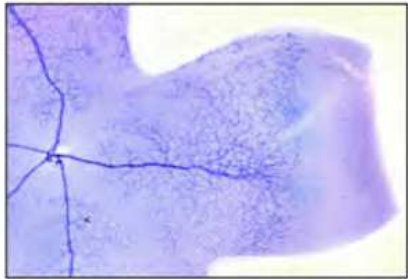

Apelin receptor is expressed in stalk cells

Fig. 11. Apelin signalling and endothelial subpopulations.

The upper left panel is a schematic representation of the formation of retinal vessels (green) driven by extension of the nervous retina (red). The upper right panel is a magnification of the migrating front of endothelial cells, with the tip cells at the leading edge and the underneath stalk cells. The lower part shows the gene expression of apelin in the front at the tip cell level (left) and apelin receptor underneath in the stalk cells (right).

\section{Apelin signalling and vascular pathologies}

\subsection{Vascular pathologies}

Besides its involvement in vessel formation, the endothelial cell is the integration center of vascular plasticity. The integration of various environmental stimuli defines its cellular response, proliferation or apoptosis, which will lead to the corresponding modification of the vascular network, extension or regression (Figure 12).

According to the previously described role of Ang2, its expression is increased by these activating environmental stimuli in order to disrupt vessel stability and initiate the vascular plasticity (Maisonpierre et al., 1997). The qualitative change of vascular network depends on the growth factor (GF) "context", which will orientate the vascular system to either extension in high GF levels or regression in low GF levels (Figure 12).

These two different modifications of the vascular network divide the vascular pathologies into ischemic diseases associated with a vessel defect and neovascularisation linked pathologies associated with a vessel excess. The ischemic pathologies primarily concern two organs, heart and leg muscle. The treatment of these pathologies requires therapeutic angiogenesis which is achieved by the use of receptor agonists of angiogenic pathways. The opposite pathologies that are characterized by neovascularisation represent more frequent and severe diseases, such as tumour neovascularisation, diabetic retinopathies and agerelated macular degeneration (AMD). For them, the therapeutic strategy is the administration of antiangiogenic molecules, such as antagonists of receptors mediating angiogenic signals. 


\section{The endothelial cell is the center of vessel plasticity}

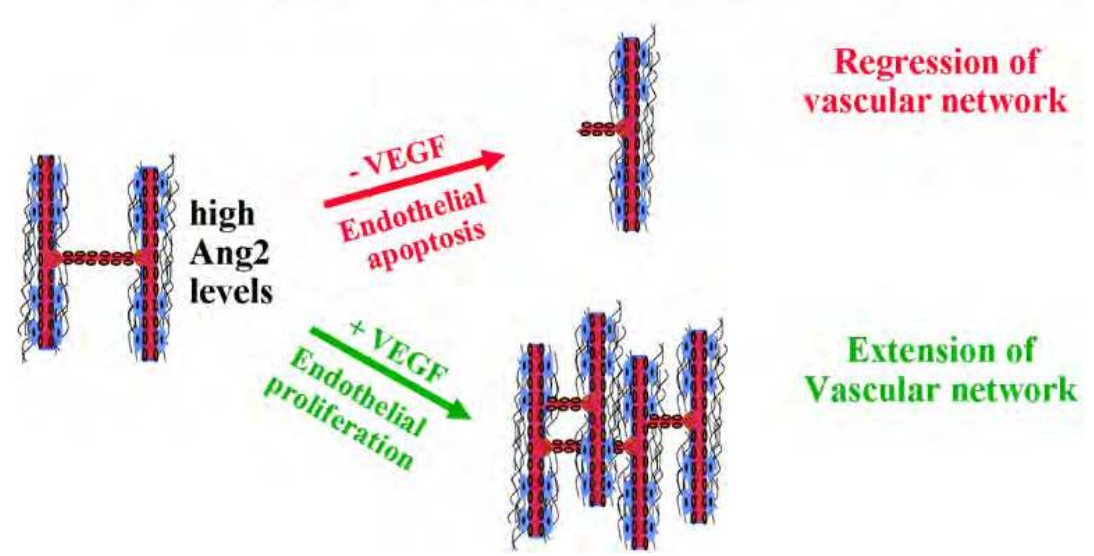

Fig. 12. Vessel plasticity and vascular pathologies.

The figure illustrates how the growth factor "context" drives the fate of vessel plasticity. Destabilization is first initiated by expression of angiopoïetin2 (Ang2) which disrupts the interaction between EC and mural cells. Low levels of VEGF induce endothelial apoptosis and lead to regression of vascular network, a situation that occurs in the ischemic diseases. In high levels of VEGF, endothelial cells proliferate, new vessels are formed, and this abnormal extension of the vascular network recapitulates what happens in the neovascular pathologies.

\subsection{Apelin signalling and vascular pathologies}

\subsubsection{Apelin signalling and ischemic pathologies}

Apelin is a potent activator of cardiac contractility (Szokodi et al., 2002), suggesting the possible involvement of apelin signalling in ischemic heart failure. Such a role is corroborated by the upregulation of apelin receptor gene in left ventricule and an increase of apelin plasma levels in left ventricular dysfunction. In addition, apelin released from the endothelium of the coronary arteries would locally act in a paracrine manner on myocardial tissue (Chen et al., 2003).

Similar data have been obtained in ischemic heart failure : total myocardial amounts of apelin and apelin receptor proteins increase in compensation of heart failure (Atluri et al., 2007). The stimuli (including tissue hypoxia) associated with heart failure upregulate transcription of ligand and receptor genes and increase their protein expression (Sheikh et al., 2008). As apelin signalling is activated for protecting the heart against ischemia injury, the effect of infusion of the endogenous agonist apelin13 was tested after ischemia. Interestingly, apelin not only limited infarct size but also improved cardiac postischemic mechanical recovery (Rastaldo et al., 2011)(Figure 13).

In limb ischemia, therapeutic angiogenesis using local delivery of genes encoding angiogenic factors or systemic injection of their recombinant proteins has proved its efficiency in promoting the revascularization of ischemic territories. In a mouse model of limb ischemia, coadministration of apelin and VEGF improves the revascularisation of the ischemic limb and induces an increase of vessel size (Kidoya et al., 2010) (Figure 13). 


\subsubsection{Apelin signalling and tumour neovascularisation}

As formulated by Folkman in 1971, the survival and growth of solid tumours depend on the formation of new vessels, which are necessary to compensate the increased oxygen demand of this highly proliferative tissue. The corollary of this hypothesis is that tumoral cells secrete angiogenic factors in order to attract host vessels and create tumoral vessels. As described for physiological angiogenesis, one activating stimulus is hypoxia occuring in the center of tumour because of its maximal distance from vessel supply.

HEART ISCHEMIA

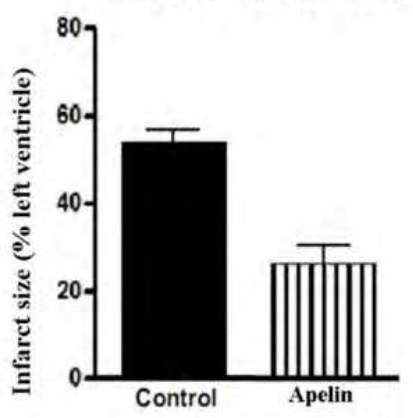

From Rastaldo et al., 2011
LIMB ISCHEMIA
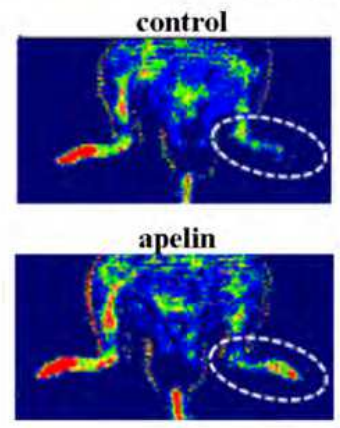

From Kidoya et al., 2010

Fig. 13. Effects of apelin in ischemic diseases.

The left part shows that the size of infarct trigged on isolated hearts is reduced by perfusion of apelin. The right part describes the angiogenic effects of apelin in limb ischemia model. Doppler images demonstrates an increase of blood flow following apelin gene transfer, which is confirmed by quantification of laser Doppler-monitored blood flow measurements.

In order to address whether apelin secreted by tumoral cells may possess a neoangiogenic activity, we developed two mouse models of tumour neovascularisation. Stable clones of B16 melanoma cells and TS/A mammary adenocarcinoma cells overexpressing apelin were created and their tumour growth was compared to that of clones transfected with the empty plasmid (named mock) (Sorli et al., 2006, 2007). Apelin overexpression clearly accelerates tumour growth in vivo and this effect results from a paracrine action on endothelial cells of host vessels (Sorli et al., 2007) (Figure 14). In addition, the number of small vessels decreases whereas that of large vessels increases (Figure 14).

The pathological relevance of apelin signalling in tumour neovascularisation was suggested by gene upregulation of apelin and its receptor in malignant gliomas, which represent highly vascularised tumours (Kälin et al., 2007). Moreover, a cancer profiling array revealed a clear upregulation of apelin gene in one third of human adenocarcinomas (Sorli et al., 2007). As far as pulmonary tumours are concerned, a recent study has confirmed that apelin mRNA levels were significantly increased in human non-small cell lung cancer (Berta et al., 2010). Interestingly, the extent and the frequency of apelin gene upregulation in a cancer profiling array was dependent on the tissue origin of the tumoral cells, the highest frequency being observed in colon (50\%) and pancreas (71\%)(Figure 15). 

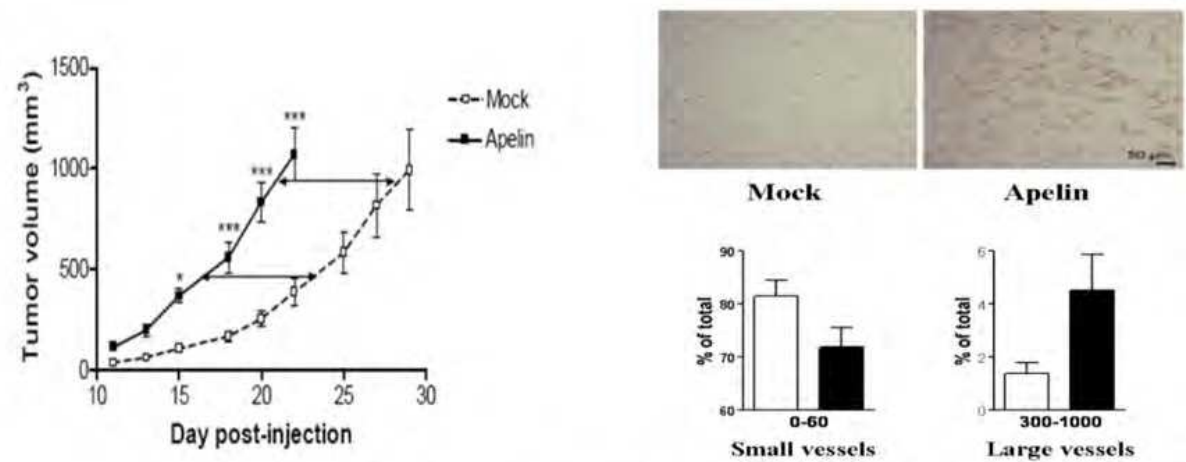

From Sorli et al., 2007

Fig. 14. Apelin overexpression and tumour neovascularisation.

Left part illustrates the acceleration of in vivo tumour growth in tumours derived from tumoral cells overexpressing apelin when compared to the animals injected with empty plasmid transfected tumoral cells (Mock). Overexpressed apelin acts on the vascular component of the tumour by increasing the total number of vessels as revealed by immunostaining with the endothelial marker CD31 (upper right panel). As shown in lower right panel, it also modifies caliber of the neovessels by increasing the number of large vessels $\left(300-1000 \mu^{2}\right)$.
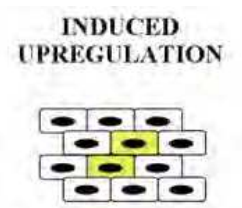

Spatially restricted to the center of tumour

Tissue independent

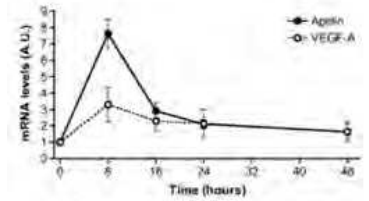

From Sorli et al., 2007

\section{CONSTITUTIVE UPREGULATION}

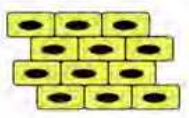

Localized in all tumoral cells

Tissue dependent

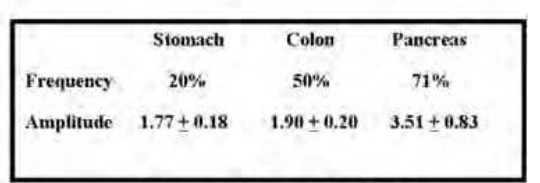

From Sorli et al., 2007

Fig. 15. Upregulation of apelin gene and tumour growth.

Two distinct modes of gene upregulation can occur during tumour neovascularisation. The hypoxia-induced upregulation is spatially restricted (yellow cells) and likely independent of the tissue origin of tumoral cells. The lower left panel shows the hypoxiainduced upregulation of apelin gene in TS/A mammary adenocarcinoma cells. On the other hand, gene upregulation may result from the genetic changes leading to the cell transformation and thus becomes constitutive (right panel). In this situation, upregulation is ubiquitous (yellow cells) and tissue dependent. As shown in the lower right panel, upregulation of apelin gene varies in frequency and amplitude from one tumoral tissue to the other. 
As the center of all tumours is hypoxic, the tissue dependent variations of gene upregulation may rather be a direct consequence of the genetic alteration(s) occurring in the genomic DNA (Figure 15). Indeed, activation of oncogenes or inactivation of tumour suppressors also leads to the upregulation of genes coding for angiogenic factors (Rak et al., 1995; Brugarolas \& Kaelin, 2004). However, such a link between genetic alterations and upregulation of apelin gene remains to be established. Altogether, the variable upregulation of apelin gene observed in human tumours may result from both genetic factors and environmental stimuli, including hypoxia.

\subsubsection{Apelin signalling and retinal neovascularisation}

Nervous retina is irrigated by two vascular networks, the retinal and the choroïdal vasculatures. The postnatal formation of retinal vessels begins at birth from the optic disk and the growing network extends in a centrifugal manner to the periphery of the retina. During formation of retinal vessels, gene expression of apelin receptor on pup retinas traces the centrifugal extension of this retinal network (see figure 10).

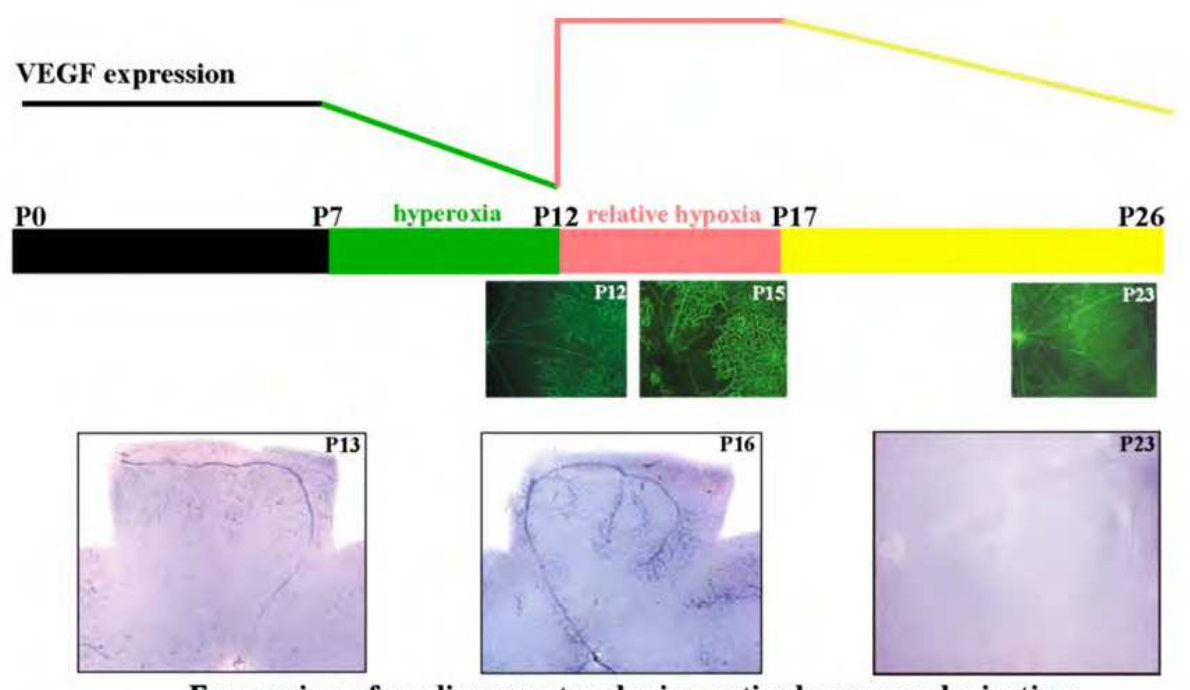

Expression of apelin receptor during retinal neovascularisation

Fig. 16. Apelin signalling and retinal neovascularisation.

The upper part describes the different steps in the mouse model of retinal neovascularisation. Hyperoxia is made between postnatal day 7 (P7) and postnatal day 12 (P12) (green) and leads to vessel regression as shown by a fluorescent marker of endothelial cells. Return to normoxia corresponds to a relative hypoxia, which triggers the formation of neovessels in a centripetal manner (see the network labelled with the fluorescent probe at P15). From P17 to P23, extensive remodelling allows recovery from hyperoxia and the retinal network becomes normal (see the network labelled with the fluorescent probe at P23). In the upper part are reported the concomitant variations of VEGF levels occurring at the different steps of neovascularisation. The lower part shows the variations of apelin receptor expression from return to normoxia until normalization of the vascular network 
The main pathological defect affecting this retinal network is observed in diabetic patients where there is an abnormal formation of new retinal vessels leading to cecity. A mouse model reproducing the main features of this retinal pathology has enabled the dissection of the molecular and cellular events during the onset and the development of this pathology (Smith et al., 1994) (Figure 16). Hyperoxia treatment of seven-day-old mice for five days induces endothelial apoptosis and decreases the number of retinal vessels. Return to normoxia corresponds to a form of hypoxia in the mid-retina, which upregulates the expression of VEGF gene and promotes the formation of new vessels. According to the localization of the ischemia in the mid-retina, the normal centrifugal extension of the forming vasculature is reversed to a pathological centripetal extension.

Interestingly, expression of apelin receptor gene is highly upregulated in these new vessels and strictly follows the centripetal extension of the retinal network (Sorli et al., 2006). In addition, quantitative analysis of apelin mRNA levels revealed a very strong increase (31fold) during the hypoxic phase; furthermore, in apelin-deficient mice, there was no increase in capillary density and abnormal vessels during the hypoxic phase (Kasai et al., 2010). Accordingly, systemic or local injection of antagonists of apelin receptor is a promising therapy for blocking the formation of new retinal vessels in diabetic retinopathies.

\subsubsection{Apelin signalling and choroïdal neovascularisation}

A frequent pathology of the elderly is the formation of excedentary vessels in the choroïdal network, which is appropriately named age-related macular degeneration (AMD). At the present time, there is no immunohistochemical study on the expression of apelin or its receptor in endothelial cells lining the choroïdal vessels. The only related observation is that apelin induces the proliferation of the immortalized choroïdal endothelial cell line RF/6A, suggesting expression of apelin receptors at the surface of these cells (Kasai et al., 2004). However, it can be assumed that the pathological angiogenesis occuring in AMD should involve the same angiogenic pathways that are activated in the formation of new vessels in the retinal network, including apelin signalling pathway.

\section{Cross-talk between angiogenic pathways}

Apelin clearly represents one of the various actors that participate in the formation of blood vessels. However, the respective role of each angiogenic pathway, including apelin signalling, as well as their synergic activity, remains to be elucidated.

A specific property of apelin peptide seems to be its ability to regulate the caliber of blood vessels by promoting the formation of enlarged vessels during physiological (Kidoya et al., 2008) and pathological (Sorli et al., 2007) angiogenesis. This vessel enlargement is one mechanism by which hemodynamic changes can respond to an increase of oxygen demand. But this effect may be indirect and due to the consequences of its cross-talk with other angiogenic pathways such as that of VEGF and Ang1 (Figure 17). The initiator of the angiogenic process would be VEGF, which induces the sprouting of endothelial cells from mature vessels and the concomitant expression of apelin receptor. Then, Ang1 via activation of its Tie2 receptor triggers the expression of apelin, which becomes secreted outside the endothelial cell. The synergic action of VEGF and apelin would lead to the proliferation of EC and the formation of cell to cell contacts. In this scenario, the precise role of apelin signalling would concern the mobilization of ECs in this assembly process and the construction of enlarged vessels. 


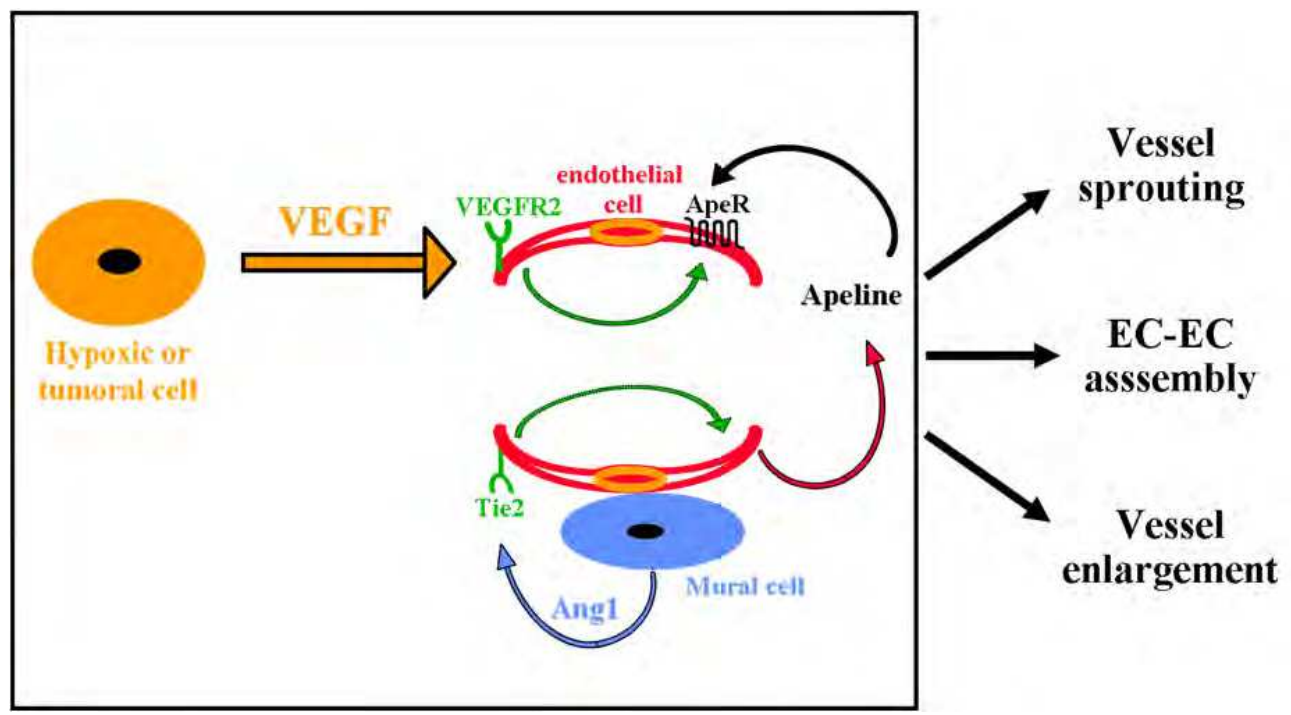

Fig. 17. Cross-talk between angiogenic pathways.

An hypoxic cell or a tumoral cell expresses VEGF gene in an induced or constitutive manner, respectively. Then VEGF activates its receptor expressed by the endothelial cell (EC), leading to increased expression of apelin receptor. In parallel, Ang1 expressed by mural cells stimulates its receptor Tie2 at the surface of EC, leading to an increased release of apelin. Apelin released in the medium can activate the same EC in an autocrine manner or another EC in a paracrine manner. All these interactions between angiogenic pathways result in vascular changes, such as vessel sprouting, EC-EC assembly and vessel enlargement.

As mentioned before, induction of genes encoding angiogenic factors by hypoxia clearly represents a crucial mechanism leading to an increased oxygen supply via extension of vascular network. However, the level of hypoxia-induced upregulation in the same cell or in various cell subtypes may vary from one angiogenic factor to the other, and thus their respective contribution may be modulated by the nature of the environmental stimuli. A same statement can be applied to tumoral cells where the genetic alterations may constitutively upregulate some angiogenic genes. In addition, as this transformationinduced modifications are extended to all tumoral cells and not restricted to the center of the tumour, the role of a specific angiogenic factor may be selectively enhanced, thereby representing a more relevant therapeutic target.

\section{Therapeutic potential of apelin signalling in vascular diseases}

As mentioned before, upregulation of the expression of apelin and its receptor is intimately associated with the angiogenic phase of vessel formation or remodelling, and their downregulation follows maturation and stabilization of the vascular structures.

These two observations have theoretical and practical consequences for vascular pharmacology. First, it reveals that apelin signalling is not a constitutive pathway at the vascular level and rather behaves as an adaptative pathway only activated during vascular 
plasticity. Second, the expression upregulation and activation of apelin signalling during angiogenesis imply that receptor antagonists may selectively target the proliferative ECs forming neovessels without affecting the quiescent ECs of stabilized vessels. These spatiotemporal properties of apelin signalling should strongly decrease the secondary effects induced by pharmacological agents targetting this pathway.

At the present time, the pharmacology of this emergent pathway is still in its infancy. The first molecule reported to act on apelin receptors was ALX40-4C, but this peptide had a very low affinity for apelin receptors and a much better affinity for CXCR4 receptors (Zhou et al., 2003). A first receptor antagonist resulting from substitution of apelin C-terminal amino acid was reported to block the hypotensive effects of apelin (Lee et al., 2005). However, in several other assays, this compound behaved as an agonist (Medhurst et al., 2003; Fan et al., 2003). Very recently, bicyclic peptides have been shown to represent competitive antagonists of apelin receptor (Macaluso et al., 2011). All these compounds are promising antiangiogenic agents for the treatment of pathological neovascularisations.

So far, only one agonist molecule has been identified and characterized (Iturrioz et al., 2010). This nonpeptidic compound behaves as an agonist in various assays, but it does not have a very high affinity. Nevertheless, it provides the structural basis for the design of better molecules, which will be used for extension of the vascular network and revascularization in ischemic diseases.

\section{Conclusion and perspectives}

The discovery of new receptors and their ligands open avenues for the design of novel pharmacological agents for treating human diseases. In addition, if the discovered signalling pathway is linked to severe diseases or lethal pathologies, the development of structurally related drugs such as nonpeptidic agonists or antagonists will lead to important clinical applications.

Apelin signalling fulfils these criteria as this emerging pathway represents a promising therapeutic target and requires the design of new pharmacological molecules in order to treat the prime causes of human mortality, such as heart failure and cancer, or severe diseases, such as limb ischemia and AMD.

\section{Acknowledgment}

I acknowledge the scientific contribution of all the people having worked with me: E. Devic, L. Paquereau, K. Rizzoti, B. Knibiehler, S. Bodin, M. Saint-Geniez, H. Mazarguil, N. Morin, M. Cornu, L. Pedebernade, L. Van den Berghe, C. Sorli, S. Le Gonidec and B. Masri.

I thank I. Scott and D. Stainier (UCSF, California) for our fruitful collaboration and our excellent scientific exchanges.

\section{References}

Atluri P, Morine KJ, Liao GP, Panlilio CM, Berry MF, Hsu VM, Hiesinger W, Cohen JE \& Joseph Woo Y. (2007). Ischemic heart failure enhances endogenous myocardial apelin and APJ receptor expression. Cell Mol Biol Lett. 12, 127-38.

Audigier, Y . (2006). Apelin Receptor. AfCS-Nature Molecule Pages doi:10.1038/mp.a000304.01 
Berta J, Kenessey I, Dobos J, Tovari J, Klepetko W, Jan Ankersmit H, Hegedus B, RenyiVamos F, Varga J, Lorincz Z, Paku S, Ostoros G, Rozsas A, Timar J. \& (2010). Apelin expression in human non-small cell lung cancer: role in angiogenesis and prognosis. J Thorac Oncol. 5, 1120-9.

Brugarolas, J. \& Kaelin JrWG. (2004). Dysregulation of HIF and VEGF is a unifying feature of the familial hamartoma syndromes. Cancer Cell 6, 7-10.

Chen, M. M., Ashley, E. A., Deng, D. X., Tsalenko, A., Deng, A., Tabibiazar, R., Ben-Dor, A., Fenster, B., Yang, E., King, J. Y., et al. (2003). Novel role for the potent endogenous inotrope apelin in human cardiac dysfunction. Circulation 108, 1432-1439.

Cho CH, Kim KE, Byun J, Jang HS, Kim DK, Baluk P, Baffert F, Lee GM, Mochizuki N, Kim J, Jeon BH, McDonald DM. \& Koh GY. (2005). Long-term and sustained COMPAng1 induces long-lasting vascular enlargement and enhanced blood flow. Circ Res. 97, 86-94.

Devic, E., Paquereau, L., Vernier, P., Knibiehler, B. \& Audigier, Y., (1996). Expression of a new $\mathrm{G}$ protein-coupled receptor $\mathrm{X}$-msr is associated with an endothelial lineage in Xenopus laevis. Mech. Dev. 59, 129-140.

Devic, E., Rizzoti, K., Bodin, S., Knibiehler, B. \& Audigier, Y., (1999). Amino acid sequence and embryonic expression of msr/apj, the mouse homolog of Xenopus X-msr and human APJ. Mech. Dev. 84, 199-203.

Dumont, D.J., Gradwohl, G., Fong, G.H., Puri, M.C., Gertsenstein, M., Auerbach, A. \& Breitman, M.L. (1994). Dominant-negative and targeted null mutations in the endothelial receptor tyrosine kinase, tek, reveal a critical role in vasculogenesis of the embryo. Genes Dev. 8, 1897-1909.

Eyries M, Siegfried G, Ciumas M, Montagne K, Agrapart M, Lebrin F. \& Soubrier F. (2008). Hypoxia-induced apelin expression regulates endothelial cell proliferation and regenerative angiogenesis. Circ Res. 103, 432-40.

Fan X, Zhou N, Zhang X, Mukhtar M, Lu Z, Fang J, DuBois GC. \& Pomerantz RJ. (2003). Structural and functional study of the apelin-13 peptide, an endogenous ligand of the HIV-1 coreceptor, APJ. Biochemistry. 242, 10163-8.

Ferrara N, Gerber HP. \& LeCouter J. (2003). The biology of VEGF and its receptors. Nat Med. 6, 669-76.

Folkman J. (1971). Tumor angiogenesis:therapeutic implications. N Engl J Med 285, 11821186.

Gerhardt H, Golding M, Fruttiger M, Ruhrberg C, Lundkvist A, Abramsson A, Jeltsch M, Mitchell C, Alitalo K, Shima D. \& Betsholtz C. (2003) VEGF guides angiogenic sprouting utilizing endothelial tip cell filopodia.. J Cell Biol 161, 1163-1177.

Glassford AJ, Yue P, Sheikh AY, Chun HJ, Zarafshar S, Chan DA, Reaven GM, Quertermous T. \& Tsao PS. (2007). HIF-1 regulates hypoxia- and insulin-induced expression of apelin in adipocytes.Am J Physiol Endocrinol Metab. 293, E1590-6.

Huang LE, Arany Z, Livingston DM. \& Bunn HF. (1996). Activation of hypoxia-inducible transcription factor depends primarily upon redox-sensitive stabilization of its alpha subunit. J Biol Chem. 271, 32253-9.

Inui, M., Fukui, A., Ito, Y. \& Asashima, M. (2006). Xapelin and Xmsr are required for cardiovascular development in Xenopus laevis. Dev Biol. 298, 188-200.

Ishida J., Hashimoto T., Hashimoto Y., Nishiwaki S., Iguchi T., Harada S., Sugaya T., Matsuzaki H., Yamamoto R., Shiota N., Okunishi H., Kihara M., Umemura S., 
Sugiyama F., Yagami K. I., Kasuya Y., Mochizuki N. \& Fukamizu A. (2004) Regulatory roles for apj, a seven-transmembrane receptor related to angiotensintype 1 receptor in blood pressure in vivo. J Biol Chem. 279, 26274-9.

Iturrioz X, Alvear-Perez R, De Mota N, Franchet C, Guillier F, Leroux V, Dabire H, Le Jouan M, Chabane H, Gerbier R, Bonnet D, Berdeaux A, Maigret B, Galzi JL, Hibert M. \& Llorens-Cortes C. (2010). Identification and pharmacological properties of E3393D6, the first nonpeptidic apelin receptor agonist. FASEB J. 5, 1506-17.

Jaffredo, T., Gautier, R., Brajeul, V. \& Dieterlen-Lievre, F., (2000). Tracing the progeny of the aortic hemangioblast in the avian embryo. Dev. Biol. 224, 204-214.

Kälin RE, Kretz MP, Meyer AM, Kispert A, Heppner FL. \& Brändli AW. (2007). Paracrine and autocrine mechanisms of apelin signaling govern embryonic and tumor angiogenesis. Dev Biol. 305, 599-614..

Kallio PJ, Okamoto K, O'Brien S, Carrero P, Makino Y, Tanaka H. \& Poellinger L. (1998). Signal transduction in hypoxic cells: inducible nuclear translocation and recruitment of the $\mathrm{CBP} / \mathrm{p} 300$ coactivator by the hypoxia-inducible factor-1alpha. EMBO J. 17, 6573-86.

Kasai, A., Shintani, N., Oda, M., Kakuda, M., Hashimoto, H., Matsuda, T., Hinuma, S. \& Baba, A. (2004). Apelin is a novel angiogenic factor in retinal endothelial cells. Biochem. Biophys. Res. Commun. 325, 395-400.

Kasai A, Shintani N, Kato H, Matsuda S, Gomi F, Haba R, Hashimoto H, Kakuda M, Tano Y. \& Baba A. (2008). Retardation of retinal vascular development in apelin-deficient mice. Arterioscler Thromb Vasc Biol. 28, 1717-22.

Kasai A, Ishimaru Y, Kinjo T, Satooka T, Matsumoto N, Yoshioka Y, Yamamuro A, Gomi F, Shintani N, Baba A. \& Maeda S. (2010). Apelin is a crucial factor for hypoxiainduced retinal angiogenesis. Arterioscler Thromb Vasc Biol. 30, 2182-7.

Kidoya H, Ueno M, Yamada Y, Mochizuki N, Nakata M, Yano T, Fujii R. \& Takakura N. (2008). Spatial and temporal role of the apelin/APJ system in the caliber size regulation of blood vessels during angiogenesis. EMBO J. 27, 522-34.

Kidoya H, Naito H. \& Takakura N. (2010). Apelin induces enlarged and nonleaky blood vessels for functional recovery from ischemia. Blood. 115, 3166-74.

Lee DK, Saldivia VR, Nguyen T, Cheng R, George SR. \& O'Dowd BF. (2005). Modification of the terminal residue of apelin-13 antagonizes its hypotensive action. Endocrinology. 2005 146, 231-6.

Levy AP, Levy NS, Wegner S. \& Goldberg MA. (1995). Transcriptional regulation of the rat vascular endothelial growth factor gene by hypoxia. J Biol Chem. 270, 13333-40.

Lindahl P, Johansson BR, Levéen P. \& Betsholtz C. (1997). Pericyte loss and microaneurysm formation in PDGF-B-deficient mice. Science 277, 242-5.

Macaluso NJ, Pitkin SL, Maguire JJ, Davenport AP. \& Glen RC. (2011). Discovery of a competitive apelin receptor (APJ) antagonist.ChemMedChem. 6, 1017-23.

Maisonpierre PC, Suri C, Jones PF, Bartunkova S, Wiegand SJ, Radziejewski C, Compton D, McClain J, Aldrich TH, Papadopoulos N, Daly TJ, Davis S, Sato TN. \& Yancopoulos GD.(1997). Angiopoietin-2, a natural antagonist for Tie2 that disrupts in vivo angiogenesis. Science 277, 55-60.

Mandal, L., Banerjee, U. \& Hartenstein, V. (2004). Evidence for a fruit fly hemangioblast and similarities between lymph-gland hematopoiesis in fruit fly and mammal aorta-gonadal-mesonephros mesoderm. Nat. Genet. 36, 1019-1023. 
Masri B, Knibiehler B. \& \&udigier Y (2005). Apelin signalling: a promising pathway from cloning to pharmacology. Cell Signal 17, 415-26.

Masri B, Lahlou H, Mazarguil H, Knibiehler B. \& Audigier Y (2002). Apelin (65-77) activates extracellular signal-regulated kinases via a PTX-sensitive G protein. Biochem Biophys Res Commun 290, 539-45.

Masri B, Morin N, Cornu M, Knibiehler B. \&EAudigier Y (2004). Apelin (65-77) activates p70 S6 kinase and is mitogenic for umbilical endothelial cells. Faseb J 18, 1909-11.

Masri B, Morin N, Pedebernade L, Knibiehler B. \& Audigier Y (2006). The apelin receptor is coupled to Gi1 or Gi2 protein and is differentially desensitized by apelin fragments. J Biol Chem. 281, 18317-26.

Masson N, Willam C, Maxwell PH, Pugh CW \& Ratcliffe PJ. (2001). Independent function of two destruction domains in hypoxia-inducible factor-alpha chains activated by prolyl hydroxylation. EMBO J. 20, 5197-206.

Medhurst AD, Jennings CA, Robbins MJ, Davis RP, Ellis C, Winborn KY, Lawrie KW, Hervieu G, Riley G, Bolaky JE, Herrity NC, Murdock P \& Darker JG. (2003). Pharmacological and immunohistochemical characterization of the APJ receptor and its endogenous ligand apelin. J Neurochem. 84, 1162-72.

O'Dowd, B.F., Heiber,M., Chan, A., Heng, H.H., Tsui, L.C., Kennedy, J.L., Shi, X., Petronis, A., George, S.R. \& Nguyen, T., (1993). A human gene that shows identity with the gene encoding the angiotensin receptor is located on chromosome 11. Gene 136, 355-360.

Plate KH, Breier G, Millauer B, Ullrich A. \& Risau W (1993). Up-regulation of vascular endothelial growth factor and its cognate receptors in a rat glioma model of tumor angiogenesis. Cancer Res 53, 5822-7.

Rak J, Mitsuhashi Y, Bayko L, Filmus J, Shirasawa S, Sasazuki TL. \& Kerbel RS. (1995). Mutant ras oncogenes upregulate VEGF/VPF expression : implications for induction and inhibition of tumor angiogenesis. Cancer Res 55, 4575-4580.

Rastaldo R, Cappello S, Folino A. \& Losano G. (2011). Effect of apelin-apelin receptor system in postischaemic myocardial protection: a pharmacological postconditioning tool? Antioxid Redox Signal. 14, 909-22.

Ronkainen VP, Ronkainen JJ, Hänninen SL, Leskinen H, Ruas JL, Pereira T, Poellinger L, Vuolteenaho O. \& Tavi P. (2007). Hypoxia inducible factor regulates the cardiac expression and secretion of apelin. FASEB J. 21, 1821-30.

Saint-Geniez M, Masri B, Malecaze F, Knibiehler B. \& Audigier Y. (2002). Expression of the murine msr/apj receptor and its ligand apelin is upregulated during formation of the retinal vessels. Mech Dev 110, 183-186.

Sato, T.N., Tozawa, Y., Deutsch, U., Wolburg-Buchholz, K., Fujiwara, Y., Gendron-Maguire, M., Gridley, T., Wolburg, H., Risau, W. \& Qin, Y. (1995). Distinct roles of the receptor tyrosine kinases Tie-1 and Tie-2 in blood vessel formation. Nature 376, 7074.

Scott IC, Masri B, D'Amico LA, Jin SW, Jungblut B, Wehman AM, Baier H, Audigier Y. \& Stainier DY. (2007). The g protein-coupled receptor agtrl1b regulates early development of myocardial progenitors. Dev Cell. 12, 403-13.

Semenza GL, Roth PH, Fang HM. \& Wang GL. (1994). Transcriptional regulation of genes encoding glycolytic enzymes by hypoxia-inducible factor 1. J Biol Chem. 269, 2375763. 
Sheikh AY, Chun HJ, Glassford AJ, Kundu RK, Kutschka I, Ardigo D, Hendry SL, Wagner RA, Chen MM, Ali ZA, Yue P, Huynh DT, Connolly AJ, Pelletier MP, Tsao PS, Robbins RC. \& Quertermous T.( 2008). In vivo genetic profiling and cellular localization of apelin reveals a hypoxia-sensitive, endothelial-centered pathway activated in ischemic heart failure. Am J Physiol Heart Circ Physiol. 294, H88-98.

Shweiki D, Itin A, Soffer D. \& Keshet E (1992). Vascular endothelial growth factor induced by hypoxia may mediate hypoxia-initiated angiogenesis. Nature 359, 843-5.

Smith LE, Wesolowski E, McLellan A, Kostyk SK, D'Amato R, Sullivan R. \& D'Amore PA. (1994). Oxygen-induced retinopathy in the mouse. Invest Ophthalmol Vis Sci 35, 101111.

Sorli SC, van den Berghe L, Masri B, Knibiehler B. \& Audigier Y. (2006). Therapeutic potential of interfering with apelin signalling. Drug Discov Today 11, 1100-1106.

Sorli SC, Le Gonidec S, Knibiehler B. \&EAudigier Y. (2007). Apelin is a potent activator of tumour neoangiogenesis. Oncogene. 26, 7692-9.

Suri C, Jones PF, Patan S, Bartunkova S, Maisonpierre PC, Davis S, Sato TN. \& Yancopoulos GD. (1996). Requisite role of angiopoietin-1, a ligand for the TIE2 receptor, during embryonic angiogenesis. Cell. 87, 1171-80.

Szokodi, I., Tavi, P. \& Foldes, G., Voutilainen-Myllyla, S., Ilves, M., Tokola, H., Pikkarainen, S., Piuhola, J., Rysa, J., Toth, M. \& Ruskoaho, H. (2002). Apelin, the novel endogenous ligand of the orphan receptor APJ, regulates cardiac contractility. Circ. Res. 91, 434-440.

Tatemoto, K., Hosoya, M., Habata, Y., Fujii, R., Kakegawa, T., Zou, M.X., Kawamata, Y., Fukusumi, S., Hinuma, S., Kitada, C., Kurokawa, T., Onda, H. \& Fujino, M. (1998). Isolation and characterization of a novel endogenous peptide ligand for the human APJ receptor. Biochem. Biophys. Res. Commun. 251, 471-476.

Thurston G, Wang Q, Baffert F, Rudge J, Papadopoulos N, Jean-Guillaume D, Wiegand S, Yancopoulos GD. \& McDonald DM. (2005). Angiopoietin 1 causes vessel enlargement, without angiogenic sprouting, during a critical developmental period. Development. 132, 3317-26.

Vodyanik MA, Yu J, Zhang X, Tian S, Stewart R, Thomson JA. \& Slukvin II. (2010). A mesoderm-derived precursor for mesenchymal stem and endothelial cells. Cell Stem Cell. 7, 718-29.

Wang GL, Jiang BH, Rue EA. \& Semenza GL. (1995). Hypoxia-inducible factor 1 is a basichelix-loop-helix-PAS heterodimer regulated by cellular O2 tension. Proc Natl Acad Sci U S A. 92, 5510-4.

Zeng XX, Wilm TP, Sepich DS. \& Solnica-Krezel L. (2007). Apelin and its receptor control heart field formation during zebrafish gastrulation. Dev Cell. 12, 391-402.

Zou MX, Liu HY, Haraguchi Y, Soda Y, Tatemoto K. \& Hoshino H. (2000). Apelin peptides block the entry of human immunodeficiency virus (HIV). FEBS Lett. 473, 15-8. 


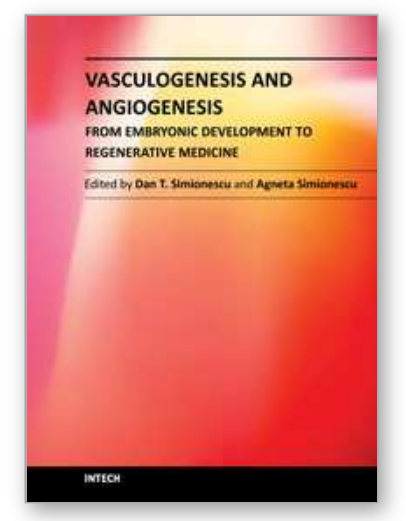

\author{
Vasculogenesis and Angiogenesis - from Embryonic Development \\ to Regenerative Medicine \\ Edited by Dr. Dan Simionescu
}

ISBN 978-953-307-882-3

Hard cover, 226 pages

Publisher InTech

Published online 07, November, 2011

Published in print edition November, 2011

Vasculogenesis is the process of new blood vessel formation during embryonic development of the cardiovascular system. This is followed by formation of a vascular tree and finally the cardiovascular system with the myriad of blood vessels that nourish all tissues and organs. Angiogenesis, on the other hand is the process by which new blood vessels take shape from existing blood vessels by "sprouting" of endothelial cells thus expanding the vascular tree. Both scenarios are based on activation, migration, proliferation and maturation of unique precursor cells. The study of blood vessel formation is an essential component of embryonic development, congenital malformations, degenerative diseases, inflammation and cancer and thus has widespread appeal to the biomedical field. Moreover, scientists are now harnessing this information for the purpose of building living blood vessel substitutes for replacement of diseased arteries and veins. This book highlights novel advances in the field of vasculogenesis and angiogenesis, including embryogenesis and development, regulation of progenitor cells, cancer and blood vessel regeneration. We consider this book a good initial source of information for graduate students, medical students and scientists interested in the intricacies of blood vessel formation, maturation, disease and replacement.

\title{
How to reference
}

In order to correctly reference this scholarly work, feel free to copy and paste the following:

Yves Audigier (2011). Apelin Signalling: Lineage Marker and Functional Actor of Blood Vessel Formation, Vasculogenesis and Angiogenesis - from Embryonic Development to Regenerative Medicine, Dr. Dan Simionescu (Ed.), ISBN: 978-953-307-882-3, InTech, Available from:

http://www.intechopen.com/books/vasculogenesis-and-angiogenesis-from-embryonic-development-toregenerative-medicine/apelin-signalling-lineage-marker-and-functional-actor-of-blood-vessel-formation

\section{INTECH}

open science | open minds

\author{
InTech Europe \\ University Campus STeP Ri \\ Slavka Krautzeka 83/A \\ 51000 Rijeka, Croatia \\ Phone: +385 (51) 770447 \\ Fax: +385 (51) 686166 \\ www.intechopen.com
}

\author{
InTech China \\ Unit 405, Office Block, Hotel Equatorial Shanghai \\ No.65, Yan An Road (West), Shanghai, 200040, China \\ 中国上海市延安西路65号上海国际贵都大饭店办公楼 405 单元 \\ Phone: +86-21-62489820 \\ Fax: +86-21-62489821
}


(C) 2011 The Author(s). Licensee IntechOpen. This is an open access article distributed under the terms of the Creative Commons Attribution 3.0 License, which permits unrestricted use, distribution, and reproduction in any medium, provided the original work is properly cited. 